\title{
Acute Coronary Syndrome with Persistent ST Segment Elevation Isolated in aVR: A Case Study
}

\section{Désiré Alain Affangla1,2*, Angèle Wabo Kandem², Wally Niang Mboup",3, Djibril Marie Ba1, Mame Madjiguene $\mathrm{Ka}^{2}$, Cheikh Mouhamadou B. M. Diop ${ }^{2,3}$, Malick Ndiaye ${ }^{2,3}$, Fatou Aw ${ }^{3}$, Stéphanie Akanni ${ }^{3}$, Adamson Phiri ${ }^{1}$, Mohamed Cor Dior Leye ${ }^{1}$, Maboury Diao ${ }^{3}$}

\author{
${ }^{1}$ Unit of Training and Research in Medical Sciences, University of Thies, Thies, Senegal \\ ${ }^{2}$ Hôpital Saint Jean de Dieu, Thies, Senegal \\ ${ }^{3}$ Department of Cardiology, Hôpital Aristide Le Dantec, Dakar, Senegal \\ Email: *docalaf@gmail.com
}

How to cite this paper: Affangla, D.A., Kandem, A.W., Mboup, W.N., Ba, D.M., Ka, M.M., Diop, C.M.B.M., Ndiaye, M., Aw, F., Akanni, S., Phiri, A., Leye, M.C.D. and Diao, M. (2020) Acute Coronary Syndrome with Persistent ST Segment Elevation Isolated in aVR: A Case Study. World Journal of Cardiovascular Diseases, 10, 67-71. https://doi.org/10.4236/wjcd.2020.102008

Received: January 6, 2020

Accepted: February 16, 2020

Published: February 19, 2020

Copyright $\odot 2020$ by author(s) and Scientific Research Publishing Inc. This work is licensed under the Creative Commons Attribution International License (CC BY 4.0).

http://creativecommons.org/licenses/by/4.0/

\begin{abstract}
A 53 years old female patient with hypertension presented with constrictive retrosternal chest pain. Initial Electrocardiogram (ECG) showed ST elevation in aVR and high level cardiac Troponin-I. Thrombolysis with streptokinase was performed and she underwent coronary angiography who showed a long tight anterior inter ventricular lesion, occlusion of the proximal circumflex and an intermediate lesion of segment 2 of the right coronary.
\end{abstract}

Keywords

Acute Coronary Syndrome, ST Elevation, aVR, Coronary Angiography

\section{Introduction}

Electrocardiogram (ECG) is the key first-line examination for the diagnosis of acute coronary syndromes. If persistent ST segment displacement is the early abnormality typical to myocardial infarction, its localization can sometimes misguide the diagnosis and management [1] [2]. We reported a rare and severe case of ST elevation myocardial infarction (STEMI) in aVR.

\section{Case Presentation}

A 53-year-old female patient was received in emergency room for acute constrictive retrosternal chest pain since 06 hours with neck, left shoulder and back radiation. She has a similar pain for one week appearing on exertion, brief and 
self-limiting. The patient is on treatment with Amlodipine and Perindopril for hypertension since 3 years. She is a nonsmoker but acknowledges her sedentary life style. Vital signs measurements were as follows: Blood Pression $=127 / 79$ $\mathrm{mmHg}$, Pulse rate $=100 / \mathrm{min}$, Respiratory rate $=20 / \mathrm{min}$, Weight $=102 \mathrm{Kg}$, Height $=1.59 \mathrm{~m}, \mathrm{BMI}=40$, Temperature $=37^{\circ} \mathrm{C}, \mathrm{SpO} 2=96 \%$.

Physical examination was normal: Pulse was full volume and symmetric and no signs of congestive cardiac failure, cardio-pulmonary auscultation was normal with regular heart sounds, and no murmurs or any supra added sounds.

Acute coronary syndrome was suspected and a ECG taken within 10 minutes showed persistent $3 \mathrm{~mm}$ ST elevation in lead aVR and depression of the ST segment in the lateral leads V4, V5, D1 and aVL (Figure 1).

Blood cardiac Troponin - I level was high $=13.46 \mu \mathrm{g} / \mathrm{l}($ normal $<0.1 \mu \mathrm{g} / \mathrm{l})$. The results of the other investigations revealed a mild dyslipidemia with total blood cholesterol $=2.28 \mathrm{~g} / \mathrm{l}, \mathrm{LDL}=1.67 \mathrm{~g} / \mathrm{l}, \mathrm{HDL}=0.51 \mathrm{~g} / \mathrm{l}$. Random blood glucose $=1.24 \mathrm{~g} / \mathrm{l}$, serum creatinine $=06 \mathrm{mg} / \mathrm{l}$ and normal blood count.

The diagnosis of an acute coronary syndrome with ST elevation was retained. Primary angioplasty was impossible to perform immediately, the patient received within 30 minutes, fibrinolysis treatment using Streptokinase.

The evolution was favorable, characterized by pain amendment, a return to the isoelectric line of the ST segment in all the leads (Figure 2), the absence of rhythm and conduction disturbances as well as signs of heart failure. Cardiac Doppler ultrasound was normal.

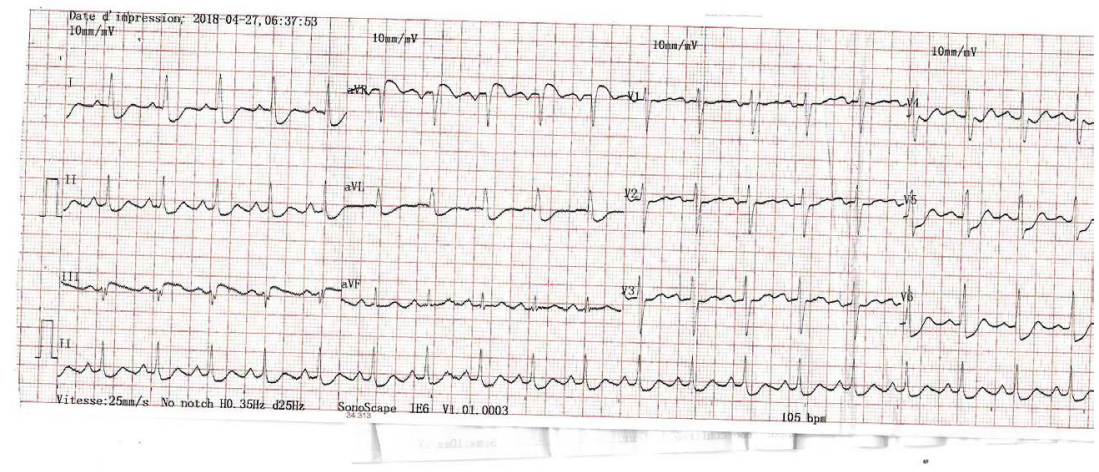

Figure 1. ECG before Fibrinolysis showing ST elevation in aVR lead.

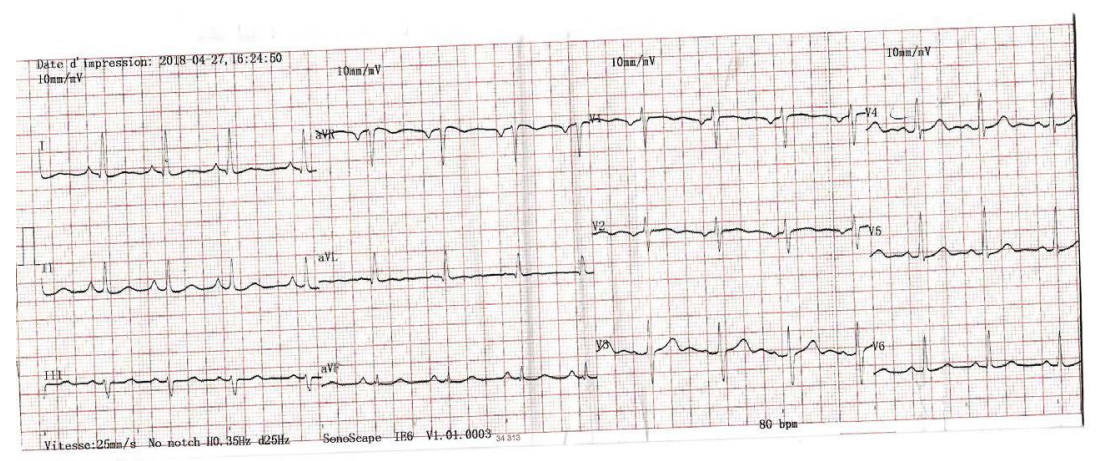

Figure 2. ECG after fibrinolysis showing a return to isoelectric line of ST segment. 
Radial coronary angiography showed a tri truncal coronary stenosis with long tight anterior inter ventricular lesion, occlusion of the proximal circumflex and an intermediate lesion of segment 2 of the right coronary (Figure 3 ). The patient successfully underwent angioplasty in Italia.

\section{Discussion}

In acute chest pain, the focus is on life-threatening etiologies: acute pericarditis, acute aortic syndrome, pulmonary embolism, and acute coronary syndrome [1]. The diagnostic strategy therefore considers the risk of acute coronary syndrome, clinical examination data, ECG results and cardiac enzyme assays [2] [3].

In our patient, the typical character of prolonged chest pain preceded by Novo's angina, the age of 53 years, sedentary lifestyle, obesity, hypertension and normal clinical examination led us to acute coronary artery syndrome.

A confirmatory ECG within 10 minutes according to the recommendations [4] was performed. In a similar context, although the diagnosis of ST + coronary syndrome is generally easy, the analysis of the aVR lead is often neglected [5]. ST segment elevation in aVR compared with a normal ST segment in V1 is strongly suggestive of myocardial infarction. In fact, occlusion of the common coronary trunk of the left coronary or of the first septal branches of the anterior inter ventricular which irrigates the basal wall of the septum below the aortic and pulmonary sigmoid valves results in an elevation of ST in aVR often related to severe coronary lesions [6] [7].

The absence of a careful analysis of the often overlooked aVR lead can be misleading, as in our patient, to the diagnosis of an acute coronary syndrome with ST segment depression in the left lateral leads V1, aVL, V4, V5, V6 corresponding to a mirror image of ST elevation in aVR The resulting consequence is that therapeutically; our patient would not have benefited from fibrinolysis according to recommendations [4] which has been effective as evidenced by the evolution in our patient.

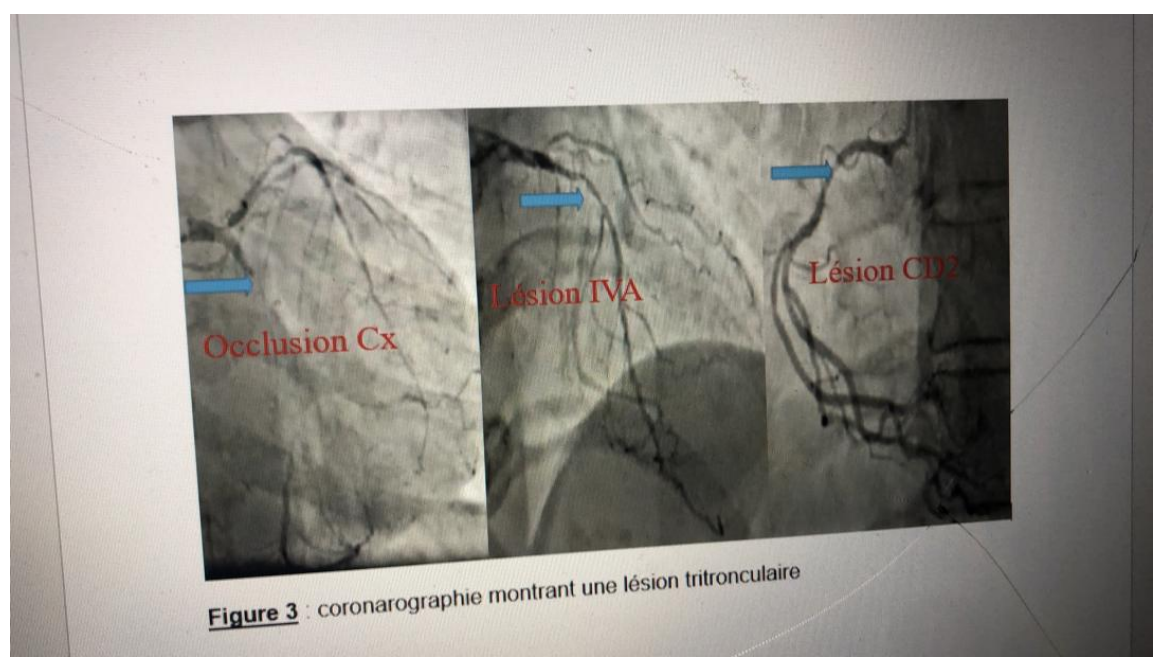

Figure 3. Radial coronary angiography showing tri truncalcoronary stenosis. 
Serum cardiac troponin I determination should not delay diagnosis and management, but may be contributory to diagnosis and follow-up [8]. Increasing serum troponin levels without consideration of ST segment elevation in aVR as in our patient would have led to a diagnosis of non-transmural myocardial infarction [4].

Coronary angiography, the reference exploration, confirmed in our patient the diagnosis of a Tri truncal coronary stenosis. In the GRACE register, 7\% to $8 \%$ of non-ST ACS have an isolated elevation in aVR, and this elevation in aVR has also been found to be a marker of severe coronary injury [9]. Our patient despite the complex lesion successfully underwent angioplasty in Italia because of the young experiences of Dakar's team [10]. Coronary angioplasty with stent implantation is the treatment of choice for coronary atherosclerosis in its various presentations [11].

\section{Conclusion}

Clinical presentation and ECG make it possible to accurately diagnose an acute coronary syndrome taking into consideration all the leads, in this case not neglecting lead-aVR.

\section{Conflicts of Interest}

The authors declare no conflicts of interest regarding the publication of this paper.

\section{References}

[1] Ray, P. and Riou, B. (2000) Démarche diagnostique devant une douleur thoracique. Médecine Thérapeutique, 6, 46-73.

[2] Levine, H.J. (1980) Difficult Problems in the Diagnosis of Chest Pain. American Heart Journal, 100, 108-118. https://doi.org/10.1016/0002-8703(80)90286-0

[3] Braunwald, E. (1997) Examination of the Patient. The History. In: Braunwald, E., Ed., Heart Disease a Textbook of Cardiovascular Medicine, WB Saunders, Philadelphie, 3-7.

[4] Steg, P.G., James, S.K., Atar, D., et al. (2012) Task Force on the Management of ST-Segment Elevation Acute Myocardial Infarction of the European Society of Cardiology (ESC): ESC Guidelines for the Management of Acute Myocardial Infarction in Patients Presenting with ST-Segment Elevation. European Heart Journal, 33, 2569-2619.

[5] Gorgels, A.P., Engelen, D.J. and Wellens, H.J. (2001) Lead aVR, a Mostly Ignored But Very Valuable Lead in Clinical Electrocardiography. Journal of the American College of Cardiology, 38, 1355-1356. https://doi.org/10.1016/S0735-1097(01)01564-9

[6] Kossaify, A. (2013) ST Segment Elevation in aVR: Clinical Significance in Acute Coronary Syndrome. Clinical Medicine Insights: Case Report, 6, 41-45. https://doi.org/10.4137/CCRep.S11261

[7] Yamaji, H., Iwasaki, K., Kusachi, S., et al. (2001) Prediction of Acute Left Maincoronary Artery Obstruction by 12-Lead Electrocardiography: ST Segment Elevation 
in Lead aVR with Less ST-Segment Elevation in Lead V1. Journal of the American College of Cardiology, 38, 1348-1354.

https://doi.org/10.1016/S0735-1097(01)01563-7

[8] Collinson, P.O., Stubbs, P.J. and Kessler, A.C. (2003) The Multicenter Evaluation of Routine Immunoassay of Troponin T Study (MERIT). Multicenter Evaluation of the Diagnostic Value of Cardiac Troponin T, CK-MB Mass, and Myoglobin for Assessing Patients with Suspected Acute Coronary Syndromes in Routine Clinical Practice. Heart, 89, 280-286. https://doi.org/10.1136/heart.89.3.280

[9] GRACE Investigators. (2001) Rationale and Design of the GRACE (Global Registry of Acute Coronary Events) Project: A Multinational Registry of Patients Hospitalized with Acute Coronary Syndromes. American Heart Journal, 141, 190-199. https://doi.org/10.1067/mhj.2001.112404

[10] Mboup, M.C., Ba, D.M., Jobe, M., et al. (2018) Coronary Angioplasty in a Low Income Sub-Saharan Country: Situational Analysis. World Journal of Cardiovascular Diseases, 8, 539-544. https://doi.org/10.4236/wjcd.2018.812053

[11] Roe, M.T., Messenger, J.C., Weintraub, W.S., et al. (2010) Treatments, Trends, and Outcomes of Acute Myocardial Infarction and Percutaneous Coronary Intervention. Journal of the American College of Cardiology, 56, 254-263.

https://doi.org/10.1016/j.jacc.2010.05.008 